\title{
Implementing E-HRM System in Developing Countries: Challenges and Prospects
}

\author{
Egwuche O. Sylvester \\ Department of Computer \\ Science \\ Federal University of \\ Technology Akure, Nigeria
}

\author{
Adewole D. Bamidele \\ Information and \\ Communication Technology \\ Application Centre \\ Adekunle Ajasin University \\ Akungba-Akoko, Nigeria
}

\author{
Olatunji S. Oluyemi \\ Department of Computer \\ Science \\ Federal University of \\ Technology Akure, Nigeria
}

\begin{abstract}
In every organization, effective Human Resource Management (HRM) is vital in order to meet the market demands with well-qualified employees at all times. The objective of this paper is to identify the challenges and prospects of implementing Electronic Human Resource Management (E-HRM) system in developing countries. Technology and HRM have a broad range of influences upon each other, and Human Resource (HR) professionals should be able to adopt technologies that allow the reengineering of the HR function, be prepared to support organizational and work-design changes caused by technology. HR technology is increasingly used by small, medium, and large employers to meet the needs of its stakeholders. What sets high-performing organizations apart from others is how they utilize cutting edge technology to deliver HR services. E-HRM provides the possibility to store and repeatedly use the information as electronic database, which could be accessible by anyone, anytime and anywhere within the organization. Maximum benefits can be derived from the use of IT by changing work processes, which can be more challenging than the purchase and integration installation of the technology itself. The analysis of this paper depends on secondary data like journals, books and, online resources.
\end{abstract}

\section{Keywords}

Personnel Management, HRM, E-Human Resource Management.

\section{INTRODUCTION}

Management affects everyone because it is present in every aspect of the world. Information technology is expected to enhance the productivity of Human Resource Management (HRM) by shifting its attention from administration or personnel management to strategic HRM. HRM is the art of managing people at work in order to achieve organizational goals [1]. The concept of E-HRM is an advance business solution which provides a rich online support in the management of all processes, activities, data and information required, to manage human resources in any organization [10]. The overall purpose of human resource management is to ensure that the organization is able to achieve success through people. Electronic HRM (E-HRM) is a term that identifies a form of technology that enables HR professionals to integrate an organization's human resources strategies and processes in order to improve overall HR service delivery. Initially HR systems were "paper-based." The use of technology within human resource management has grown considerably over the years. Technology can also be used to provide HR information and to enable managers and employees to perform simple HR tasks themselves. The concept of Electronic Human Resource Management known as E-HRM meaning "the adoption of technology in delivering Human Resource practices due to the digital revolution in the world is such a tool that organizations can employ to manipulate the performance and behavior of the employees to achieve business success [10]. IT is beginning to enable organizations to deliver state-of-the-art HR services, and reduced costs have enabled companies, regardless of the firm size-to purchase HR technologies. Advances in IT hold the promise of meeting many of the challenges of HRM, such as attracting, retaining, and motivating employees, meeting the demands for a more strategic HR function, and managing the "human element" of technological change in the future.

\section{REVIEW OF RELATED LITERATURE}

The increased use of web technology to deliver HR will leave HR specialists more time for strategic decision making and that outsourcing of people-management activities will liberate HR specialists to perform more strategic activities [11].

[6] Noted that the management of HR is complex and problematic because the individuals as workers rarely adapt or voluntarily embrace the objectives of the organization. As individuals, the employees have needs, aspirations, motivations, desires and interests which influence their behavior at work but unfortunately these objectives are sometimes in conflict with the corporate objectives of the enterprise. In reconciling this conflicting interests, Human Resources Management and Planning are useful tools that can harmonize the needs of the employees with the goals and objectives of the organization on a continuous basis. [9] Noted that information technology has the potentials of bridging the gap between theory and practice in human resource management studies. Businesses invest in information systems as a way to cope with and manage their peculiar production functions and to cope with the demands of key actors in their environments. Information flow is therefore a determining factor in the success of any business ventures [8].

The costs of implementing IT in any organization go beyond purchasing the technology to providing training and systems support. Many benefits can be derived from the integration of IT by changing work processes, which can be more challenging than the purchase and maintenance of the technology itself [5]. While an organization's founders and other top executives define the organization's vision, strategies and policies, it is the responsibility of managers and supervisors to interpret the vision as well as to implement and 
to execute these strategies and policies [2]. IT professionals are able to function best when they understand the total objectives; clearly understand their role in the organization; recognize technology's part in driving the organization's goals; and feel that the values of the organization are respected [7]. The tasks of sourcing and managing talented employees can be made much easier by managers through cross cultural training, technological and informational training of HR people and motivation of employees through available techniques. Information technologies are among the most important tools for achieving current [16] business firms' key objectives.

\section{SYSTEM OVERVIEW 3.1 Evolution of Human Resources Technology}

HR technology can be defined as any technology that is used to source and manage employees in an organized working environment. This technology can be used in different types of human resource information systems (HRIS) and by various stakeholders, such as managers, employees, and HR professionals. This technology can be accessed in different ways [15]. There is no doubt that technology has made it easier and faster to gather, collate, and deliver information and communicate with employees. It is pertinent to note that this innovation has the potential to reduce the administrative burden experience by HR department. Research has shown that companies who effectively use technology to manage their HR functions will have a significant advantage over those that do not [18].

\subsection{Electronic Database System}

The emergence of relational database technology provides organizations with the ability to develop more complex reports that integrates several data elements. A relational database allows databases to be established in several different locations and the information linked. For example a report could be generated from different databases that include name, address, and salary.

In recent time, use of the Internet was increasing, and HR continued to own the HR data, but HR began to evolve into a more integral part of the business, as these databases became important in aiding HR with the generation of reports and empowering HR to provide managers with meaningful HRrelated information. In addition, other functional areas could share information from these databases [3].

\subsection{Web-Based Technology}

At the present time, many companies have started to embrace HR technology. The benefits of automation are becoming widely known to HR and other areas of the business. The focus has shifted to automating as many transactions as possible to achieve effectiveness and efficiencies [12].

\subsection{Electronic Human Resources}

Electronic HR (E-HR) is a term that identifies a form of technology that enables HR professionals to integrate an organization's human resources strategies and processes in order to improve overall HR service delivery. Companies are always looking for better ways to manage costs, provide better service, and effectively manage human capital, and E-HR has become integral to helping organizations achieve these goals. HR technology includes:

\subsubsection{Paper-Based System}

Initially HR systems were "paper-based." These systems operated independently and did not integrate with any other business-related functions. Features were added as needed. Data were typically stored on mainframe computers, the reporting was very rudimentary, and HR was the sole custodian of the data. It was common for managers during this period to send employees to HR to get all their "personnel" questions answered.

\subsubsection{Early Personal Computer (PC) Technology}

In the next stage, there was a migration of the information resident in these paper-based systems to PCs and local area network (LAN) systems. Advances in database technology included payroll and some very basic versions of employee tracking. The HR data were typically stored on a client/server - a network architecture in which each computer on the network is either a client or a server. Servers are powerful computers dedicated to managing disk drives (file servers), printers (print servers), or network traffic (network servers). Clients rely on servers for resources, such as files; devices, such as printers; and even processing power.

\subsubsection{Electronic Database System}

The next stage began with the emergence of relational database technology. A relational database means that a piece of data can be stored in more than one file, each one containing different types of data. The different files can be linked so that information from the separate files can be used together. A relational database allows databases to be established in several different locations and the information linked. This technology provided organizations with the ability to develop more complex reports that integrated several data elements. With this move toward electronic databases, HR systems began to become integrated with other business-related systems. Leading HR organizations began to purchase enterprise-wide systems that included HR-related modules. An enterprise-wide system is defined as a system that supports enterprise-wide or cross-functional requirements, rather than a single department or group within the organization. For example a report could be generated from different databases that included name, address, and salary and benefit information.

\section{CHALLENGES OF E-HRM}

Information/evidence based decision making is not yet a culture adopted in many organization of developing countries. There is shortage of personnel, equipment and financial resources that are essential for information collection, analysis, dissemination and use.

However, not all companies have the latest and greatest technology, nor do all companies need the most advanced technology, but all companies do have HR-related information needs.

One challenge in E-HR is the alignment of processes in the HR function according to the future of e-business challenge. From the findings of [17] several challenges were pointed such as lack of funding to acquire, update, and maintain critical HRIS, lack of expertise(s) in IT to operate the HRIS because of the reluctance of the organizations to train, educate and develop the employee.

Government institutions are increasingly growing in developing countries but it is observed that the existing government structures are weak in performing their statutory 
responsibilities. Human societies have advanced to a stage that one government cannot infinitely govern the people therefore; change in government has come to stay. But, developing countries suffer lack of continuity in the ideas and policies of past administrations. Hence, policy somersault in terms of IT penetration for effective HR administration affects the steady growth of organizations in such societies. Hindrances to some of these ideas and policies include;

- Insufficient financial support

- Problems with time management of the HRIS implementation process and the need to work with other departments

- Fear of changing the way staff do things

- The HRIS not being perceived as an advantage

- Lack of commitment and involvement by all employees and lot of paper work that is difficult to computerize undermined the achievement of the full potential of HRIS.

Deriving benefit from IT generally means changing work processes, which can be more challenging than the purchase and installation of the technology itself [4].

There are many communities around the developing societies today who are cut off from Internet connection. In every part of any nations, youths with requisite employable skills exits but situations become more difficult for citizens of that category if the mode of recruiting workers to their workforce is carried out on electronic platform. More so, existing telecommunication industries in developing countries offer poor quality of service which is necessitated by digital divide, poor maintenance culture, lack of technical know-how, and mismanagement of public funds by the government of the day. Imagine how the best can be derived from a HRIS system that is meant to run for 24 hours in a society that experience epileptic power supply.

One crucial fact that is not far from any developing society is insecurity which slows down the pace of development in most of these countries. Long term investors plan to go far in the business world and no investor will pool his resources together and invest in any societies where the safety of his facilities is bleak. Therefore, insecurity of lives and property impedes the penetration of IT in any countries.

Leadership development also proves to be a big challenge. HR professionals continue to wrestle with understanding the best ways to keep people in the pipeline and develop leaders for future succession planning. HR professionals are expected to provide the essential frameworks, processes, tools, and points of view needed for the selection and development of future leaders.

Implementing change in any system in the local context is a big challenge in the dynamic human society. Bureaucracy can also be a problem, presenting the need to consider doing things differently in order to eliminate bottlenecks and red tape.

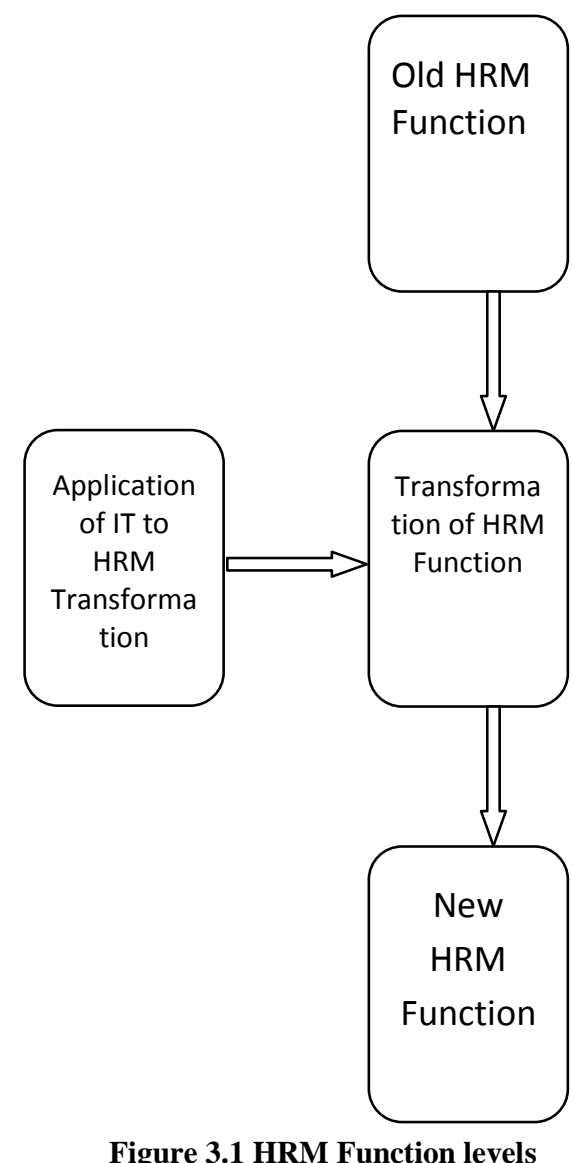

5. BENEFITS OF E-HRM

Information Technology is a tool to facilitate the collection, analysis, dissemination and use of information. It includes hardware and software for the support of organizational information. IT offers many ways to improve the quality of service, help staff to make better use of their time and expertise and promote greater efficiency [18].

The biggest benefit of using IT in HRM to organizations is the freeing of HR staff from intermediary roles which enable them to concentrate on strategic planning in human resource organization and development. In the present context of increasing globalization, employing organizations and their environments have become increasingly complex. Managers of cross- cultural organizations are facing growing difficulties in coping with workforces that may be spread across a variety of countries, cultures and political systems. Given such trends, IT has considerable potential as a tool that managers can utilize to increase the capabilities of the organization [14]

The reasons behind an organization's introduction of an HRIS may vary considerably from the need to facilitate efficient processes or cut costs, to improve communication and customer service, or the desire to create a shift in the role of the HR function from one that is mainly administrative to one that is more strategic. Using HRIS technology can help HR automate and simplify tasks, reduce administration and record keeping, and provide management with HR-related information when required.

\section{CONCLUSION}

Drivers of investment in information technology include the promise of quality and efficiency gains. Barriers include the 
cost and complexity of IT implementation, which often necessitates significant work process and cultural changes.

Some of the strategies put forward to counteract the challenges were ensuring that the sources of funds to cover the costs of setting up and maintaining a HRIS, mobilization of financial resources, support from top management, training of staff on how to operate E-HRM, staff attitude change towards information technology, sourcing for the required expertise(s) and timeliness during the implementation stage.

Strategies must continually be redefined to deliver improved return on investment in human capital. As HR professionals work within their own organizations, they must also cope with good and bad economies and, new technology. Because of the numerous potentials of E-HRM in developing societies, policy makers need to better understand how information technology is diffusing across providers, whether action to spur further adoption is needed, and if so, what steps might be taken. Any policy to stimulate further investment must be carefully considered because of the possibility of unintended consequences - such as implementation failures due to organizations' inability to make the necessary cultural changes.

\section{REFERENCES}

[1] Abdullah H. (2009). Major Challenges to the Effective Management of Human Resource Training and Development Activities Ding, W. and Marchionini, G. 1997 A Study on Video Browsing Strategies. Technical Report. University of Maryland at College Park.

[2] Agarwal, R., \& Ferratt, T. W. (2002). Toward understanding the relationship between IT human resource management systems and retention: An empirical analysis based on multiple theoretical and measurement approaches. Proceedings of the 2002 ACM SIGCPR Conference on Computer Personnel Research, Kristiansand, Norway, pp. 214-225.

[3] Debra A. M., Donald D . D., Thomas D . F., Janis S., \& Joan M. (2007). Managing Human Resources In Information Technology: Best Practices Of High Performing Supervisors. Wiley Periodicals, Inc. Vol. 46, No. 3, Pp. 411-427.Sannella, M. J. 1994 Constraint Satisfaction and Debugging for Interactive User Interfaces. Doctoral Thesis. UMI Order Number: UMI Order No. GAX95-09398., University of Washington.

[4] Ekta S., \& Nisha A. (2012), The Emerging Challenges in HRM; International Journal Of Scientific \& Technology Research Volume 1, Issue 6.

[5] First Consulting Group (2003). Computerized physician order entry: Costs, benefits and challenges, a case study approach. Prepared for American Hospital Association and Federation of American Hospitals Y.T. Yu, M.F. Lau,
"A comparison of MC/DC, MUMCUT and several other coverage criteria for logical decisions", Journal of Systems and Software, 2005, in press.

[6] Francis C. A., Cyril O. I., \& Samuel E. (2011). Human Resource Management Challenges In Nigeria Under A Globalised Economy; International Journal of Economics and Management Sciences Vol. 1, No. 4, pp. 01-11

[7] Glen, P. (2003). Leading geeks: How to manage and lead people who deliver technology. San Francisco, CA: Jossey-Bass.

[8] Haag, S., \& Cummings, M. (2008). Management information systems for the information age. New York, USA: McGraw Hill.

[9] Johan G. (2009). The use of information technology in contemporary HRM; Research School Management \& IT, Uppsala University.

[10] Kovach, K., Hughes, A., Fagan, P., \& Maggitti, P. (2002). Administrative and strategic advantages of HRIS

[11] Kulik C. T., \& Perry, E. L. (2008). When less is more: The effect of devolution on HR strategic Role and Donstrued Image, Human Resource Management, 47(3), pp.541-558.

[12] Michael A. (2006); A Handbook of Human Resource Management Practice; 10th Edition.

[13] Shashank K. S. (2010). Shaping Organization with eHRM; International Journal of Innovation, Management and Technology, Vol. 1, No. 1. Pp 1 -4.

[14] Tansley C. \& Watson T. (2000). Strategic exchange in the development of human resource information systems (HRIS). New Technology, Work and mployment, 15 (2), 108-122.

[15] Varma S. \& Gopal R. (2011). The Implications of Implementing Electronic-Human Resource Management (E-HRM) Systems in Companies; Journal of Information Systems and Communication; Vol. 2, Issue 1, pp 10-29

[16] Yasemin B., Serdar B., Esin E., (2012). The Importance of Using Human Resources Information Systems (HRIS) and a Research On Determining The Success Of HRIS.

[17] Tumuhirwe O. (2011); A Research Report Submitted to Makerere University Business School in Partial Fulfilment of the Requirements for the Award of Degree of Masters in Human Resource Management of Makerere University.

[18] Yu L. (2009), The impact of information technology on the HR function transformation; Master Thesis, Business Administration HRM University of Twente. 